\title{
A CONSTRUÇÃO DA IDENTIDADE URBANA NO SÉCULO XIII. O CASO DO SUL DE PORTUGAL
}

\author{
Hermínia Vasconcelos Vilar ${ }^{1}$ \\ Universidade de Évora /CIDEHUS
}

\section{RESUMO}

Conquistado entre a segunda metade do século XII e o final da primeira metade de Duzentos o Sul de Portugal e a rede de centros urbanos aí existente protagonizaram processos próprios de construção de discursos identitários e de consagração politica de determinados grupos sociais.

A partir de um núcleo diferenciado de fontes no interior do qual se articulam as representações figurativas utilizadas por alguns dos concelhos urbanos do Sul de Portugal, como é o caso dos selos e os primeiros textos legislativos produzidos para ou no interior destas localidades, como é o caso dos forais e dos usos e costumes, procuramos traçar as linhas orientadoras dos discursos identitários construídos neste período e identificar alguns dos seus responsáveis.

Neste contexto torna-se visível o domínio da guerra como argumento legitimador de uma estrutura social desigual e de elemento básico na construção de uma identidade local em especial num contexto cronológico mais recuado, ao mesmo tempo que se define uma evolução desse discurso no sentido da valorização dos critérios económicos e de legitimação do domínio de determinados grupos sociais.

Palavras-Chave: Identidade Urbana, hierarquia social, guerra, sigilografia municipal, legislação municipal.

1 Doctora en Historia. Profesor Auxiliar. Departamento de Historia. Centro Interdisciplinar de História, Culturas e Sociedades (CIDEHUS). Universidade de Evora. 7000. Evora (Portugal).C.e.: hmav@uevora.pt. 


\begin{abstract}
Conquered between the second half of the 12th century and the end of the first half of the 13th century, the South of Portugal and the net of urban centers existing there were responsible for the construction of self identity discourses during the last centuries of Middle Ages.

From a differentiated nucleus of sources in which we included municipal seals as figurative representations of an identity and the first legislatives texts produced by or for this cities, as was the case of «forais» and of letters of customs, we have tried to define the main subjects of this discourses, the arguments of legitimacy that were used and the beneficiaries of this discourses.

In this context war was, in fact, a main argument of legitimacy of a social hierarchy defined by the first charters and a crucial element of identity specially during the 12 and 13 th centuries.
\end{abstract}

Keywords: Urban identity, social hierarchy, war, municipal seals, municipal legislation.

\title{
1. ENTRE CAVALEIROS E CIDADÃOS
}

«Aos 6 dias de Fevereiro de 1324 (ano de 1286) em a cidade de Evora Stevam Garcia, alcaide, Rodrigo Eanes e Lourenço Gonçalves, juízes então de Evora e o concelho da dicta cidade se juntarom en a cidade en o adro de Santo António apres dessa igreja (...) e ho dito muito alto senhor Dom Denis estando presente en sa pessoa no dicto logar com muitos da sa corte, o dicto concelho mandou leeer hua sua petiçom»².

Assim se inicia um documento lavrado em Évora nos primeiros dias de Fevereiro de 1286 , autenticado por seis tabeliães desta cidade, tantos quantos, provavelmente, existiam ao seu serviço nestes últimos anos do século XIII e testemunhado por um amplo leque de personagens cuidadosamente inventariadas no final do diploma. Personagens que surgem incluídas numa longa lista que compreende não apenas os nomes de cada um dos presentes mas também pequenas indicações sobre as ligações familiares de muitos dos que eram mencionados e que permitiriam, possivelmente, a um utilizador deste diploma, uma rápida integração destes homens nas famílias e nos grupos dominantes no espaço urbano.

E, com efeito, a importância local do conjunto de testemunhas que se apresentam como garantes era clara o que atesta a solenidade do documento que então foi exarado bem como a relevância dos assuntos que nele foram incluídos. Na verdade, neste início de Fevereiro D. Dinis encontrava-se em Évora, cidade aliás à qual re-

2 Gabriel Pereira, Documentos Históricos da Cidade de Évora, Lisboa, Imprensa Nacional- Casa da Moeda, 1998, pp. 42-44. 
gressaria ainda outras vezes no decurso do seu longo reinado que se prolongaria até $1325^{3}$, e aí, no adro da igreja de Santo António, o concelho e vários homens bons dirigiram ao rei os seus pedidos no sentido do reconhecimento de um conjunto variado de privilégios, que íam desde a confirmação do direito deste concelho de não ser dado a rico homem e logo a manutenção do seu estatuto de concelho régio, já incluído no foral de 1166, até ao pedido de construção de uns novos e maiores açougues, face à incapacidade de recuperar os já existentes, passando pela regulamentação das relações entre oficiais, nomeadamente entre o alcaide de nomeação régia e os oficiais concelhios, tema ao qual não raras vezes o concelho retornaria nos anos seguintes, agravado pelo abuso do exercício da autoridade do máximo representante régio. A todos estes pedidos D. Dinis, então presente, respondeu favoravelmente, recebendo em troca o reconhecimento concelhio de todos os direitos e bens que seu pai aí tinha tido, reconhecimento que vinha, muito possivelmente, no seguimento de uma inquirição sobre os herdamentos e reguengos detidos pelo rei em Évora e no seu termo, mas levada a efeito no ano anterior ou seja em $1285^{4}$.

Sendo um acordo celebrado entre o rei e o concelho e perante o rei e membros da sua corte, não surpreende a solenidade com que se procurou rodear a sua celebração e mesmo a sua redacção. No entanto, o que nos interessa neste diploma específico e que considerámos como ponto de partida desta análise é a já referida lista de testemunhas incluída no final do documento e na qual foi inventariado um conjunto de cerca de quarenta indivíduos directamente ligados ao exercício do poder concelhio ou às elites dos cavaleiros, cidadãos e mercadores de Évora e que como tal são identificados. Na realidade, esta extensa lista constitui a mais antiga e pormenorizada abordagem que possuímos para a caracterização possível dos grupos que se articulavam em torno do exercício do poder concelhio desta cidade do Sul de Portugal e os lacónicos e poucos dados adicionais utilizados na caracterização das diferentes personagens mencionadas possibilita-nos o estabelecimento de um conjunto de questões sobre a composição social destas élites locais, sobre o modo de articulação com o exercício do poder concelhio no final da centúria de Duzentos mas também sobre a imagem que a cidade projectava da sua própria organização interna ${ }^{5}$.

3 José Augusto de Sotto Mayor Rodrigues, D. Dinis, Lisboa, Círculo de Leitores, 2005 e Virginia Rau, Itinerários Régios Medievais. Elementos para o Estudo da Adminstração Medieval Portuguesa. I - Itinerário del-rei D. Dinis (1279-1325) (dir. de), Lisboa, Instituto de Alta Cultura, 1962.

${ }^{4}$ Gabriel Pereira, ob. cit., pp. 40-42.

5 Sobre algumas das questões ligadas ao conceito de élites aplicado às cidades medievais veja-se a Introdução de Elisabeth Crouzet-Pavan intitulada «Les Élites urbaines: aperçus problématiques (France, Angleterre, Italie» ao Colóquio Les Élites Urbaines au Moyen Âge, XXVIIe Congrès de la SHMES (Rome, May 1996), Rome, École Française de Rome, 1997 pp. 9-28 e o estudo de Philip Daileader, True Citizens. Violence, Memory and Identity in Medieval Perpignan, Leiden, Brill, 2000. 
No caso concreto desta análise interessam-nos em especial as questões decorrentes do último nível de reflexão enunciado ou seja o que se prende com a imagem projectada pela cidade da sua própria organização interna, sobre os grupos que a compõem e os critérios que os identificam. Grupos que assumem perante o rei uma postura de procura de reafirmação de direitos e privilégios muitas vezes incluídos num quadro legislativo anterior e que poderão ter protagonizado, de forma diferenciada, a construção dos pilares de uma seminal identidade urbana saída da guerra da Reconquista ${ }^{6}$.

$\mathrm{Na}$ verdade, a ordem que subjaz ao rol de testemunhas adicionado no final do documento constitui um primeiro ponto de partida para a apreensão não apenas de uma imagem de desigualdade que estrutura a lista enunciada mas dos próprios factores de diferenciação social que cruzavam e dividiam estas elites ${ }^{7}$.

Assim e antes de mais a lista estabelece uma clara diferenciação entre os representantes dos diferentes arrabaldes da cidade e os restantes habitantes, oriundos do núcleo urbano. Na verdade, nas últimas linhas do elenco foram incluídos os nomes dos representantes dos arrabaldes da Porta de Alconchel, de S. Francisco, da Porta de Moura e de S. Mamede ${ }^{8}$. Arrabaldes que a nova cerca construída nas décadas seguintes viria a incluír no perímetro amuralhado ${ }^{9}$, mas que, em meados da década de 80 do século XIII, funcionavam ainda como excrescências ao primitivo núcleo definido pela cerca romano-muçulmana e resultantes do crescimento que a cidade tinha conhecido, pelo menos desde o momento da sua conquista pelos cristãos, cerca de um século antes $^{10}$. Desta forma, era retraçada e reafirmada a sempre presente clivagem entre vizinhos da cidade e habitantes do termo, assimilando-se, contudo, a noção de termo não ao espaço indiferenciado que rodeava a cidade, mas antes a quatro pólos organizadores do espaço, directamente confinantes com a muralha e coincidentes com os arrabaldes identificados tanto em termos espaciais como sociais e diferenciados do núcleo central da cidade. No que respeita especificamente a este último, a hierarquia social parecia organizar-se de uma outra forma e sujeitar-se a diferentes critérios.

6 Sobre a importância desta cronologia veja-se o artigo de Jean- Claude Maire Viguer, «Les inscriptions du pouvoir dans la ville. Le cas de l' Italie communale (XIIe-XVe siêcles), in Villes de Flandre et d' Italie (XIIIe-XVIe siècle)- Urban History 12, dir. De Élisabeth CrouzetPavan and Élodie Lecuppre- Desjardin, Turnhout, Brepols, 2008, pp. 207-234.

7 Ver nota 5 e ainda Philippe Braunstein, «Pour une histoire des élites urbaines: vocabulaire, réalités et représentations», in Les Élites Urbaines au Moyen Age, pp. 29-38.

8 Gabriel Pereira, ob. Cit, p. 44.

9 Sobre a construção da cerca nova veja-se Ângela Beirante, Évora na Idade Média, Fundação Calouste Gulbenkian- Junta Nacional de Investigação Cientifica e Tropical, 1995, pp. 46-51 $\boldsymbol{e}$ Miguel Lima, O Recinto amuralhado de Évora, Lisboa, Estar Editora, 1996.

${ }^{10}$ Hermenegildo Fernandes e Herminia Vilar, «O Urbanismo de Évora no período medieval», Monumentos, 26 (2007), pp. $6-15$. 
Com efeito, cerca de trinta nomes constituem o grosso desta lista de representantes do núcleo central da vila. Personagens identificadas, primeiro, como cavaleiros e que ocupam os lugares cimeiros deste rol de testemunhas e um segundo grupo de indivíduos definidos como cidadãos, conjunto bem mais restrito, intercalado entre os cavaleiros e os representantes dos arrabaldes.

Curiosamente, e ao contrário do que uma análise mais rápida poderia fazer supôr, o autor ou autores da lista não se parecem ter preocupado em identificar as funções que estas diferentes personagens poderiam exercer no concelho. Além da menção específica e particular ao alcaide e aos juízes, feita logo no início do diploma, o concelho é referido no seu todo sem qualquer menção específica aos seus constituintes. Para a identificação das funções exercidas por algumas destas personagens ou do papel exercido por algumas destas familias teremos de nos socorrer de outro tipo de documentos, um pouco mais tardios. Pelo contrário, o que parece hierarquizar as personagens referidas é, em primeiro lugar, a pertença ao grupo dos cavaleiros ou dos cidadãos e no interior destes, critérios de carácter social ou parental em detrimento do tipo de funções exercidas, talvez porque decorrentes estas das primeiras e não o contrário.

Com efeito e a par destes elementos de caracterização social e funcional, a maior parte das testemunhas leigas mencionadas são-no prioritariamente em função de relações de parentesco. É assim que encontramos irmãos bem como tios e sobrinhos, com apelidos comuns, apelidos que encontramos já em alguns documentos anteriores datados da década de 60 do século XIII e que veremos perpetuarem-se nas elites desta cidade ao longo das décadas seguintes ${ }^{11}$.

Identificados como cavaleiros ${ }^{12}$ eles poderão representar os possíveis herdeiros dos primeiros possidentes e dos grupos directamente beneficiados pela conquista cristã. No seu interior poder-se-ão encontrar, possivelmente, os descendentes mais ou menos directos dos cavaleiros que o foral de 1166 destacava dos demais habitantes da cidade e que distinguia pelo seu poder económico mas também pelo lugar especializado que ocupavam na economia da guerra opondo-os aos peões ${ }^{13}$ mas também aqueles que se apropriaram dessa herança

${ }^{11}$ Ângela Beirante, ob. cit., Herminia Vilar, «Canons and cities: cathedral chapters and social composition in the medieval Portugal», E- Journal of Portuguese History, 2008, vol. 5, nº 2, $19 \mathrm{pp}$.

12 Sobre a noção da cavaleiro vilão veja-se José Mattoso, Identificação de um país. Ensaio sobre as origens de Portugal (1096-1325), 2 vols, Lisboa, Editorial Estampa, 1985, vol. I -Oposição, pp. 345-358.

${ }^{13} \mathrm{O}$ texto deste foral pode ser encontrado em Gabriel Pereira, ob.cit., pp. 17-19 e nos Documentos Medievais Portugueses, introdução e notas de Rui de Azevedo, Lisboa, Academia Portuguesa de História, 1958, Tomo I, pp. 371-373 e sobre o seu texto veja-se o estudo de Marcelo Caetano, Os forais de Évora, separata do Boletim da Junta Distrital de Évora, no 8, Évora, Gráfica Eborense, 1969. 
e protagonizaram a organização urbana no decurso das primeiras décadas. A alguns destes cavaleiros de origem vilã e aos seus descendentes, os séculos finais da Idade Média trariam a tão desejada nobilitação, mas, no entretanto, o seu estatuto parecia oscilar entre os referenciais da guerra que identificavam o seu lugar e a sua função no campo militar e uma influência concretizada na detenção de cargos concelhios.

Diferentes eram, possivelmente, os critérios utilizados na identificação do grupo de cidadãos. Na verdade, cavaleiros e cidadãos não surgem como termos usados de forma aliaetória, mas parecem-nos antes apelarem para diferentes universos, organizados de acordo com critérios díspares.

Com efeito, se os cavaleiros poderiam ser entendidos ou confundidos com aqueles que tinham construído uma parte do seu poder sobre o lugar ocupado na estrutura guerreira, ou seja como herdeiros directos dos cavaleiros que tinham assegurado a defesa senão mesmo a conquista da cidade em meados do século XII ou se tinham apropriado do seu domínio após a conquista, a noção de cidadão poderá apelar para uma outra realidade emergente, para personagens e famílias cuja legitimidade não encontrava raízes no estatuto guerreiro, mas antes no poder económico mais recentemente adquirido ${ }^{14}$. Talvez isso explique, em parte, algumas especificidades do grupo de nomes aí incluído, onde parece dominar a utilização de alcunhas como terceiro nome ou mesmo em substituição de patronímico (Beiçudo, Barregam ou Chumbado) ou o apelo a uma profissão exercida pelo próprio ou por um ascendente, como é o caso de Martim Afonso dito ferreiro, enquanto os cavaleiros se identificam predominantemente em função de um nome, de um patronímico e não raras vezes em função de um terceiro nome que assume já o contorno de um nome da família ${ }^{15}$ porque utilizado por membros de um mesmo conjunto parental.

A ausência destes terceiros nomes como elementos identificadores dos «cidadãos» poderá ser lida como indiciadora da recém chegada de muitas destas personagens aos meios oligárquicos da cidade ou da fragilidade da organização familiar destes individuos e da sua representatividade, mas cuja presença e in-

\footnotetext{
${ }^{14}$ Martin Aurell, «La Chevalerie urbaine en Occitanie (fin Xe- début XIIIe siêcle)», in Les élites urbaines au Moyen Âge, pp. 71-118 e Mário Farelo, A Oligarquia camarária de Lisboa(1325-1433), dissertação de Doutoramento em História Medieval apresentada à Faculdade de Letras da Universidades de Lisboa-policopiada, 2008, especialmente pp. 169-223.

${ }^{15}$ Iria Gonçalves, «Identificação medieval: o nome dos dirigentes concelhios em finais de Trezentos», Revista Portuguesa de História, tomo XXXI, vol. 2, 1996, pp. 103-127 e da mesma autora, «Amostra de antroponímia alentejana no século XV», in Imagens do Mundo Medieval, Lisboa, Livros Horizonte, 1988, pp. 69-104.
} 
fluência junto ao restante concelho se apresentava já como central à obtenção de um consenso local ${ }^{16}$.

Uma análise mesmo que generalista deste rol de testemunhas coloca-nos, pois, perante dois níveis diferenciados de fractura interna que convirá assinalar desde já. Um reiterava uma divisão já tradicionalmente atestada em estudos dedicados aos meios urbanos e que radica na eterna diferenciação estabelecida e reproduzida entre os vizinhos e os moradores do termo e que neste documento se corporiza em torno dos arrabaldes da cidade. A outra era estabelecida entre cavaleiros e cidadãos ou seja entre grupos que sustentavam a legitimidade do seu predomínio ou as bases da sua ascensão em critérios distintos e em percursos cronologicamente diferenciados e que, como tal, constituíam diferentes grupos ou facções no interior dos grupos dominantes de uma cidade. Aceitando-se esta premissa como verdadeira, a história da coexistência, articulação ou oposição destes grupos é um campo de análise que apenas a documentação das décadas posteriores permite compreender mas que constitui, a nosso ver, uma perspectiva privilegiada de análise da evolução da própria cidade e da capacidade do seu corpo social em integrar diferentes estratos numa hipotética oligarquia dominante ${ }^{17}$.

Um outro dado a realçar a partir da análise desta lista radica nas referências à presença de parentes que aí é feita. Não parentes identificados individualmente e aos quais já atrás fizemos referência, mas designações que apontam no sentido da existência de uma «parentela» que acompanhava determinado indivíduo ${ }^{18}$. Nestes casos poderemos estar perante grupos de dimensão desconhecida, unidos por laços de parentesco mais ou menos distantes senão mesmo por relações de dependência confundidas ou equiparadas a uma noção extensa de parentela. Mas o que estas referências deixam também entrever é um determinado exercício de poder e de organização dos grupos que os exercem, baseado ainda em

\footnotetext{
${ }^{16}$ A bibliografia sobre a gestão camarária em Portugal é relativamente numerosa em especial para períodos mais avançados. Veja-se a título de referência Adelaide Millan da Costa, Vereação e Vereadores: o governo do Porto em finais do século XV, Porto, Câmara Municipal-Arquivo Histórico, 1993 e Maria Helena Coelho, «O Estado e as sociedades urbanas» in A Génese do Estado Moderno no Portugal tardo-medievo, Lisboa, Universidade Autónoma de Lisboa, 1999, pp. 269-292.

${ }^{17}$ A discussão em torno da constituição das oligarquias dominantes tem originado uma ampla bibliografia nomeadamente espanhola e que permite interessantes e profícuas comparações. Entre as várias obras destaquem-se os artigos inseridos na Colecção Studies in European Urban History, o $\mathrm{n}^{\circ} 19$ intitulado Oligarchy ans Patronage in late Medieval Spanish Urban Society, dir. de Maria Asenjo-González, Turnhout, Brepols, 2009, o estudo de Juan António Barrio Barrio, «Una oligarquia fronteiriza en el Mediodia valenciano. El patriciado de Orihuela, siglos XIII-XV, separata de Revista d' Historia Medieval, 9 e de José Antonio Jara Fuente, Concejo, poder y elites. La clase dominante de Cuenca en el siglo XV, Madrid, CSIC, 2000.

${ }^{18}$ Gabriel Pereira, ob. cit., p. 43.
} 
famílias ou parentelas alargadas que não raras vezes corporizavam facções e confrontos que amiúde transbordavam para as ruas da cidade.

E Évora não é a este título uma excepção. Diferentes momentos da sua vivência interna foram marcados por lutas entre facções, cuja violência e importância ficaram, em alguns casos, gravadas na memória escrita de alguns registos, como aconteceria algumas décadas mais tarde, no início do século XIV, quando a eleição do bispo de Évora disputada entre vários candidatos, alguns de origem local, deu origem a um curioso rol de queixas sobre os desacatos praticados pela parentela de um dos candidatos nas ruas da cidade ${ }^{19}$.

A estrutura hierarquizada que este documento reflecte é, pois, bem mais complexa do que a patente nas fontes legislativas que marcam o primeiro enquadramento jurídico da cidade, ou seja o foral de 1166 e em parte os costumes de Évora, produzidos, possivelmente, em meados de Duzentos ou ainda na sua primeira metade. Ditada pelos condicionantes de uma sociedade guerreira, a hierarquia vigente nos documentos produzidos nas primeiras décadas de existência da cidade pós reconquista, ou seja posterior a 1165, reproduzia uma ordenação baseada em critérios guerreiros, dividindo a população nos grupos tradicionais de cavaleiros e peões e subordinava a estes critérios os decorrentes de uma ordenação económica. Pelo contrário, as fontes das últimas décadas de Duzentos parecem reproduzir o lento insinuar de novos ditames de organização social sob a estrutura reproduzida nos textos jurídicos, permitindo, desta forma, entrever o lento processo de alteração ou de crescente complexificação de uma imagem criada no contexto da guerra de fronteira, e situar este período como um ponto de chegada de um processo que se articula com a criação e definição de uma identidade urbana e da sua assunção por parte de determinados grupos.

A questão colocada parte, assim, do pressuposto de que falar de um processo único de construção ou de definição de uma identidade urbana no decurso dos séculos centrais e finais da Idade Média tem implicito a assunção por protagonistas, nem sempre identificados, da liderança de um processo com fins e objectivos determinados e prosseguido ao longo destes séculos. Contudo, tal análise não implica o desfavorecimento de uma abordagem que atente na variação e flutuação dos objectivos perseguidos e dos núcleos polarizadores do discurso urbano ${ }^{20}$ e nas contingências regionais de evolução dessa construção. Ou seja, os riscos inerentes à criação de visões teleológicas e plenamente definidas nos seus con-

${ }^{19}$ Hermínia Vasconcelos Vilar, As Dimensões de um poder. A Diocese de Évora na Idade Média, Lisboa, Editorial Estampa, 1999, pp. 79-85.

${ }^{20}$ Isabel del Val Valdivieso, «La identidad urbana al final de Edad Media», Anales de Historia Medieval de la Europa Atlântica, no 1,2006 p. 5-28 é um bom ponto de situação de algumas das questões e dos trabalhos feitos em torno do processo de construção da identidade urbana no reino de Castela. 
tornos e finalidades entre os séculos XIII e XV são enormes senão atendermos à articulação de diferentes fases nestes processos de construção e de reconstrução de identidade ou identidades urbanas, fases essas marcadas pela progressiva e inevitável adaptação das cidades às contingências conjunturais das alianças políticas e dos condicionalismos de uma estrutura económica também ela mutável. Desta forma, teremos ainda de ter presente que as cidades não constituem centros produtores unificados de um discurso de identidade mas que compreendem no seu interior diferentes níveis discursivos geradores de identidade, nem sempre coincidentes entre si, se bem que nem sempre esses níveis questionem a existência de um discurso dominante de identidade protagonizado e assumido pela oligarquia política urbana ${ }^{21}$. Discurso esse que poderá não acarretar, obrigatoriamente, níveis de singularidade absoluta que os permitam distinguir de outros discursos de identidade produzidos em âmbitos urbanos semelhantes, mas antes apelar para condicionalismos conjunturais comuns determinados pela relação entre poderes, nomeadamente entre o poder local e o rei.

Para atestar da operacionalidade ou não desta visão e tendo em linha de conta a existência de diferentes fases na construção de um discurso identitário urbano optámos pela análise de um espaço geográfico : o Sul de Portugal, articulado prioritariamente em torno de três cidades: Évora, Elvas e Beja e de uma cronologia mais recuada que, no caso do território português, se confunde com o período de consolidação territorial e de definição das estruturas económicas após a conquista cristã, ou seja entre a segunda metade do século XII e o início da segunda metade de Trezentos e escolhemos 2 níveis de questões: um prendese com a identificação de alguns dos elementos simbólicos de identificação e de reconhecimento externo utilizados pelos concelhos numa fase embrionária da sua organização e do seu papel na criação de uma possível identidade urbana e neste campo optámos pela interrogação prioritária dos símbolos utilizados na sigilografia municipal. Um segundo nível de interrogações prende-se com a análise da acção e a produção escrita, mormente legislativa, que visam o reconhecimento interno, ou seja por parte da comunidade urbana, o estabelecimento das regras de convivência social e traçam os limites do enquadramento legal e da articulação dos núcleos urbanos com o poder real nas primeiras décadas da sua existência. Para tal os forais e os costumes que pontuam os séculos XII e XIII constituem fontes privilegiadas a par das cartas régias produzidas nestas décadas e dirigidas a estes núcleos.

${ }^{21}$ Marc Boone, «Les pouvoirs et leurs représentations dans les villes des anciens Pays -Bas (XIVe-XVe siècle)», in Ville de Flandre et d' Italie (XIIIe-XVIe siècle). Les enseignements d'une comparaison, pp. 175-206 sobre a questão do reflexo dos poderes e dos discursos de poder no espaço urbano. 
Ao considerarmos o Sul de Portugal como ponto de partida para a nossa reflexão em detrimento de espaços mais a Norte considerámos igualmente como critério estudar como um território conquistado entre a segunda metade do século XII e o final da primeira metade de Duzentos desenhou o seu discurso de identidade e de inserção num reino que, paulatinamente, se definia e se construía.

Apesar de tudo as três localidades consideradas como base de análise apresentam significativas diferenças tanto na sua organização interna como no seu percurso e trajectória ao longo do período considerado. Assim, Évora foi conquistada pelo primeiro rei de Portugal em 1165 tendo-se mantido na posse dos cristãos desde essa data apesar das invasões de 1190-91 de Yakub Al- Mansur e do impacto almohada. Gradualmente e ultrapassada a fase da guerra, Évora foi ganhando influência e importância política e económica. Sede episcopal desde, pelo menos, 1166, Évora ganhará sob domínio cristão uma proeminência de que não usufruíu sob o domínio muçulmano, tornando-se nos séculos finais da Idade Média local de permanência privilegiada da corte régia ${ }^{22}$. Curiosamente, no período muçulmano, esse domínio tinha cabido a Beja, cidade central do espaço do Al-Gharb Al-Andalus ${ }^{23}$, e pólo de uma região agrícola particularmente rica que determinou a sua disputa prolongada entre cristãos e muçulmanos até 1232-3424. Foi também já nas primeiras décadas do século XIII, talvez pouco antes de 1229, que Elvas terá sido ocupada pelos portugueses após a conquista de Cáceres por Afonso IX de Leão facto que conduziu ao desmembramento de uma série de fortificações muçulmanas que se espraiavam pela área de influência de Cáceres $^{25}$. Cidade de fronteira entre Portugal e Leão, Elvas constituíu desde cedo um baluarte de defesa e vigilância da fronteira portuguesa e esse estatuto marcou a sua organização espacial e política ${ }^{26}$.

Para um contexto cronológico como este não abundam os registos individuais urbanos produzidos pelas instâncias concelhias ou por outros centros locais e a própria identificação das elites políticas e económicas torna-se difícil face à escassez de dados empíricos. Contudo, a importância seminal deste período na identificação de uma cidade parece-nos inegável e central na compreensão da existência ou não de um processo de construção de um discurso identitário.

22 Sobre Évora veja-se a obra já citada de Ângela Beirante, Évora na Idade Média.

${ }^{23}$ Christophe Picard, Le Portugal musulman (VIIIe-XIIIs siècle). L' Occident d' Al-Andalus sous domination islamique, Paris, 2000, pp. 187-190.

${ }^{24}$ Maria Alegria Marques, «As etapas de crescimentos do reino» in Nova História de Portugal, vol. III - Portugal em Definição de fronteiras, dir de Maria Helena Coelho e Armando Carvalho Homem, Lisboa Editorial Presença, 1996, pp. 43-44.

${ }^{25}$ Ibidem

${ }^{26}$ Fernando Branco Correia, Elvas na Idade Média, dissertação de mestrado em História Medieval apresentada à Faculdade de Ciências Sociais e Humanas da Universidade Nova de Lisboa-policopiada, 1999, especialmente o vol. III sobre Elvas cristã. 


\section{A REPRESENTAÇÃO URBANA: OS LIMITES DE UMA IMAGEM}

No final do documento acima referido o concelho e o rei afirmavam que, de forma a que o acordado tivesse maior firmeza, o selavam com os seus selos, ou seja com o selo de D. Dinis e com o selo do concelho, a par dos sinais dos sete tabeliães presentes. Curiosamente esta é uma das primeiras e mais antigas referências à existência do selo do concelho de Évora, tendo em conta que a primeira data de 1251 e consta de um diploma de acordo estabelecido com o mosteiro da Trindade de Santarém ${ }^{27}$, embora o original que validou o documento de 1286 não tenha sobrevivido.

É possível, contudo, que a imagem usada no selo de 1286 não se diferenciasse da utilizada cerca de 30 anos antes e que incluía um guerreiro a cavalo com elmo redondo, escudo e lança, rodeado de uma inscrição identificadora do concelho ${ }^{28}$. Representação que, de forma mais ou menos semelhante, vemos repetir-se em outros espaços da cidade como acontece num dos alçados exteriores da Sé de Évora, onde se encontra uma representação em baixo-relevo de um cavaleiro, cuja descrição e pormenor de composição é, neste caso, francamente mais exigente do que a presente no selo e ao qual se juntou a representação de duas cabeças, uma feminina e uma masculina, com reminiscências muçulmanas que encimam o guerreiro a cavalo, sendo símbolos prováveis da derrota dos islâmicos à mão dos cristãos. Para Armando Pereira ${ }^{29}$ é possível que este conjunto escultórico tenha sido elaborado nos anos 40 do século XIV aquando do último grande ciclo de construção da catedral eborense no período medievo e que teve lugar sob a protecção do bispo D. Pedro ${ }^{30}$ e no rescaldo da vitória de Afonso IV na batalha do Salado ${ }^{31}$.Uma imagem semelhante, oriunda possivelmente da segunda metade do século XIV, mas com um menor grau de perfeição, foi igualmente incluída na «Casa de ver-o-peso», ou seja no local onde se aferia o peso de qualquer mercadoria ${ }^{32}$ por ordem do concelho e que se viria a localizar não longe do sítio onde em 1286 o concelho se tinha reunido com D. Dinis, na chamada Praça Grande, mais tarde Praça do Geraldo.

${ }^{27}$ D. Luís de Gonzaga de Lancastre e Távora, O Estudo da Sigilografia Medieval Portuguesa, Lisboa, 1983, exemplar nº 189, pp. 193-194.

${ }^{28}$ Seguimos a descrição de D. Luís Gonzaga de Lancastre e Távora e que a refere como uma gravação arcaica, datável dos inicios do século XIII ou mesmo de finais do século XII. D. Luís Gonzaga de Lancastre e Távora, O Estudo da sigilografia...., pp. 193-194.

${ }^{29}$ Armando Pereira, Geraldo Sem Pavor. Um guerreiro de fronteira entre cristãos e muçulmanos $c$. 1162-1176, Porto, Fronteira do Caos Editores, 2008, pp. 18-22

30 Ana Maria Borges, «A acção mecenática do bispo D. Pedro» in Eborensia, Revista do Instituto Superior de Teologia de Évora, no 39-40, 2007, pp. 117-136.

${ }^{31}$ Bernardo Vasconcelos e Sousa, D. Afonso IV, Lisboa, Círculo de Leitores, 2005, pp. 210-219.

32 Armando Pereira, ob. cit, pp. 23-24. 
De qualquer forma, o guerreiro a cavalo parece ter funcionado como imagem emblemática de Évora desde o final da primeira metade do século XIII, difundida através dos selos municipais que surgem a validar documentação destas décadas de Duzentos mas usada, igualmente, em diferentes espaços de influência concelhia. Um guerreiro foi igualmente a imagem que Elvas adoptou para o seu selo municipal ${ }^{33}$, apresentando as duas representações inegáveis semelhanças entre si.

É possível que esta escolha se tivesse estendido a outros concelhos no decurso do século XIII. Contudo os levantamentos sigilográficos feitos até agora em Portugal não o permitem afirmar. Pelo contrário, o catálogo realizado por D. Luiz Gonzaga de Lancastre e Távora em 1983 inclui apenas a imagem e descrição de cerca de 25 selos de diferentes municípios ${ }^{34}$, número possivelmente pouco representativo do conjunto de selos municipais existente e de entre este número apenas os selos de Évora e Elvas apresentam esta imagem.

À semelhança do que aconteceu com os documentos emanados pela realeza, pela nobreza ou pelos membros das instituições eclesiásticas desde relativamente cedo que os selos foram utilizados pelos concelhos como elementos de validação dos documentos ou dos actos incluídos e descritos nos diplomas. Contudo e como já foi realçado por vários autores, a sua utilização não terá sido tão numerosa como se poderia pensar nem extensível a todo e qualquer tipo de documento emanado pelo concelho. Com efeito o selo municipal, e a este nível Portugal não é excepção, não parece ter sido utilizado de forma sistemática, pelo menos no decurso das centúrias de Duzentos e de Trezentos ${ }^{35}$, como forma de validação de todos os actos municipais. Os estudos de caso já realizados apontam no sentido de que a sua utilização foi feita maioritariamente em função de uma representação externa do selo ou seja a sua aposição concretizou-se em documentos dirigidos ao exterior ou que consagraram acordos entre diferentes instituições, em detrimento de uma utilização sistemática.

Desta forma, a utilização do selo municipal parece ter respondido, predominantemente, à necessidade de provar externamente a intervenção do concelho em diferentes contextos, não correspondendo a uma forma de validação de toda a documentação emanada. Contudo e apesar destas limitações, a importância

33 D. Luís de Gonzaga de Lancastre e Távora, ob.cit, p. 199.

${ }^{34}$ D. Luís de Gonzaga de Lancastre e Távora, ob.cit. Veja-se a abordagem feita por Maria Helena Coelho, «Concelhos», in Nova História de Portugal - vol. III- Portugal em definição de fronteiras, pp. 563-565 e de Maria Helena Coelho, José Marques e Armando Luís de Carvalho Homem, «Diplomatique municipale portugaise (XIIIe-Xve siècles)», La Diplomatique urbaine en Europe au Moyen Âge, Louvaina, Garant, 2000, pp. 281-306.

35 José Marques, Maria Helena Coelho e Armando Carvalho Homem, ob. cit. 
simbólica do selo e da sua utilização não é questionável já que, tal como Brigitte Bedoz-Rezak realçou o selo municipal não se identifica em função de uma pessoa mas de um colectivo e, em paralelo, personifica e personaliza o colectivo que representa ${ }^{36}$. Daí a importância da imagem através da qual o concelho se fazia representar.

Não obstante o pequeno número de selos municipais conhecidos para Portugal ${ }^{37}$, tal como já atrás foi referido, um levantamento das imagens incorporadas nestes selos coloca algumas questões para as quais nem sempre é fácil obter uma resposta.

Como seria de esperar a variabilidade de representações é acentuada. Desde as imagens que incluem animais como acontece com os selos de Penalva, Sortelha ou de $\operatorname{Trancoso}^{38}$, aos elementos vegetais como arbustos ou árvores ${ }^{39}$, passando por elementos como barcas, no caso de Lisboa ${ }^{40}$, a representação de uma cabeça feminina, por vezes coroada, como acontece com o selo de Coimbra ${ }^{41}$ ou mais vulgarmente de panos de muralhas ou de castelos, os diferentes modelos utilizados são relativamente numerosos, se bem que circunscritos a algumas dezenas de exemplares.

Contudo, a acentuada dependência em relação às contingências que marcam a sobrevivência documental, dificulta o estabelecimento de qualquer datação para a origem da utilização do selo municipal e como tal não permite articular, de forma linear, o início da sua utilização ou a escolha de uma imagem com determinados contextos históricos. Da mesma forma, o pequeno número de selos municipais inventariados não autoriza, na maior parte dos concelhos, a construção de qualquer percepção sobre a existência ou não de uma evolução da representação sigilográfica. O concelho de Coimbra é a este título uma excepção. Localidade detentora de um dos selos municipais mais antigos que se conhece para Portugal, ostenta numa primeira fase, 1205, a representação de uma santa coroada como se fosse rainha, para mais tarde, no início de Trezentos incluir além do busto feminino a imagem de um cálice ou de uma pia baptismal, de uma serpente, de um ramo de árvore e das armas reais ${ }^{42}$.

${ }^{36}$ Brigitte Bedos- Rezak, «Le sceau médièval et son enjeu dans la diplomatique urbanine en France» in La Diplomatique Urbaine en Europe, pp. 23-44 em especial pp.. 41-42.

${ }^{37}$ Em França o Corpus de selos minicipais reúne 739 selos. B. Bedos, Les Sceaux des villes in Corpus des sceaux français du Moyen Age, I, Paris, 1980

${ }^{38}$ D. Luís de Gonzaga de Lancastre e Távora, ob.cit, exemplares no 41, 58 e 121.

${ }^{39}$ Ibidem, exemplares $n^{\circ} 133$ e $\mathrm{n}^{\circ} 120$.

${ }^{40}$ D. Luís de Lancastre e Távora, Idem, no 67 e nº 137.

${ }^{41}$ Ibidem, exemplares no 99, 152 e 248-249.

${ }^{42}$ Saul Gomes, Introdução à Sigilografia Portuguesa, guia de estudo, Coimbra, Faculdade de Letras da Universidade de Coimbra, p. 106. 
A inclusão das armas reais a partir do século XIV em alguns selos municipais não deixa aliás de ser revelador da crescente ligação e dependência das cidades em relação ao poder real e da assunção que é feita pelas elites que corporizam e assumem a memória e a identificação da cidade da ligação privilegiada ao monarca e que fazem do privilégio de não serem dadas em prestâmo a nenhum rico-homem um assunto de reconfirmação recorrente.

No caso de Lisboa o selo incorpora a imagem de uma barca sobre as águas, símbologia que invoca, possivelmente, a localização litoral da cidade mas também a emblemática vicentina ligada ao culto de $\mathrm{S}$. Vicente e à fundação do mosteiro de S. Vicente na segunda metade do século XII, pouco após a conquista cristã $^{43}$. Na verdade, os paralelismos traçáveis entre a simbologia utilizada no selo concelhio, no selo do mosteiro vicentino e mesmo em alguns selos sobreviventes do cabido da Sé de Lisboa, que incorporam nas suas representações, se bem que com particularidades, a imagem da barca reflecte a partilha, aparentemente pouco comum, de uma simbologia e coloca inevitáveis questões sobre a existência de um fundo comum de representação e de identificação da cidade ${ }^{44}$.

Curiosamente este parece ser um dos poucos casos que incorpora elementos religiosos, tal como acontece adicionalmente nos selos dos concelhos de Belmonte e de Vila da Feira, nos quais a figura da Virgem surge, respectivamente, a par da representação de um pano de muralhas e de um castelo ${ }^{45}$. Neste contexto, a inserção de símbolos religiosos na iconografia municipal portuguesa parece ser menos importante do que em outros espaços como é o caso da França na qual a inclusão da simbologia devocional atinge percentagens bem mais significativas ${ }^{46}$, o que não deixa de colocar algumas questões sobre os níveis de articulação entre os poderes locais e os eclesiásticos e a incorporação desta simbologia.

${ }^{43}$ Veja-se a Introdução de Maria João Branco ao estudo A Conquista de Lisboa aos Mouros. Relato de um cruzado, edição de Aires A. do Nascimento, Lisboa, Vega, 2001 e ainda de Maria João Branco, «Reis, bispos e cabidos:a diocese de Lisboa no primeiro século da sua restauração», in Lusitania Sacra, 2 a série, X (1998), pp. 55-94 e Carlos Guardado da Silva, O Mosteiro de S. Vicente de Fora. A comunidade regrante e o património rural (sécs XII-XIII), Lisboa, Ed. Colibri, 2002

${ }^{44}$ A apropriação da simbologia vicentina por parte das autoridades municipais continuaria aliás nas décadas seguintes mesmo no decurso da centúria de trezentos já que data de 1346 um dos mais belos selos municipais identificados como originário do concelho de Lisboa e que inclui três níveis de representação com a descrição de diferentes situações que são tradicionalmente identificadas como ligadas à recepção das reliquias de S. Vicente pelo rei D. Afonso Henriques de Portugal e pelo bispo de Lisboa. Saul Gomes, ob. Cit, pp. 107-108.

${ }^{45}$ D. Luís de Gonzaga de Lancastre e Távora, ob.cit, exemplares no 290 e 364.

${ }^{46}$ Christian de Mérindol, «Iconographie du sceau de ville en France à l'époque médièvale et religion civique» in La Religion Civique à l' époque médièvale et moderne (Chrétienté et Islam), Roma, École Française de Rome, 1995, pp. 415-428. 
A existência de um fundo comum ou melhor de uma tendência comum a vários selos municipais é também a conclusão que se pode retirar quando se comparam selos como os de Castelo Mendo, Parada ou Santarém, entre outros. Nestes dominam as representações de panos de muralha ou de castelos estilizados, simbólica incontestavelmente ligada à guerra e à defesa mas também à afirmação de um poder, fomalizado na representação da muralha ou do castelo que rodeava a vila que se fazia representar. Mas estas não eram as únicas formas de invocação da guerra.

Concelhos como os de Évora e de Elvas, como já referimos, escolherão outros formas de invocação das campanhas militares. Aqui predomina o uso da figura do guerreiro a cavalo alusivo não apenas aos contingentes de cavaleiros com que o concelho devia contribuir para a defesa da cidade ${ }^{47}$ mas também ao papel que os habitantes da cidade tinham desempenhado na defesa da cidade e na conquista e ocupação do seu termo a partir da segunda metade do século XII, tal como é mencionado e definido nos respectivos forais. Ou seja sendo estes selos uma invocação da guerra e da importância da mesma nos equilíbrios locais, em especial no decurso das décadas iniciais da existência da cidade, a verdade é que esta representação apela igualmente para o papel desempenhado pelos cavaleiros vilãos nesta guerra. O que significa que, na primeira metade do século XIII ou em meados de Duzentos, quando este selo começa a ser utilizado os concelhos de Évora e de Elvas identificam-se ainda externamente em função da guerra e do seu papel nesta actividade.

Claro que a utilização desta representação não se limitou ao sul de Portugal. Imagens semelhantes podem ser encontradas em selos municipais oriundos de outros espaços geográficos como a França ou mesmo Castela e o mesmo ocorre com as gravações que incluem a representação de castelos ou de panos de muralha, comuns em selos oriundos de diferentes reinos da Europa Ocidental ${ }^{48}$.

Neste contexto, o estudo da geografia de difusão destas representações é central embora aparentemente secundarizado nas investigações, tal como já foi realçado por Brigitte Bedoz- Rezak ${ }^{49}$, e deve ter em conta não apenas os circuitos de difusão e de influência dentro de um reino mas entre diferentes espaços políticos, no sentido de apreender paralelismos de representação ao nível da sigilografia municipal à semelhança do que já foi feito para a sigilografia régia ${ }^{50}$.

\footnotetext{
${ }^{47}$ Maria Helena Coelho, «Concelhos», in Nova História de Portugal, p. 564.

${ }^{48}$ Martine Fabre, Sceau médièval. Analyse d' une pratique culturelle, Paris, L' Harmattan, 2001, pp. 150-153.

${ }^{49}$ Brigitte Bedoz-Rezak, ob. Cit..

${ }^{50}$ Robert- Henri Bautier, «Échanges d' influences dans les chancelleries souveraines du Moyen Age, d' après les types des sceaux de majesté» in Chartes, sceaux et chancelleries, vol. II, pp. 563-591.
} 
De qualquer forma, os circuitos de difusão destas imagens não questionam a afirmação de autoridade e de autonomia que a sua utilização reflectia.

No caso especifico de Évora a memória da cidade tenderá, igualmente, a confundir essa representação com a de Geraldo Sem Pavor, um guerreiro de fronteira responsável pela conquista da cidade em $1165^{51}$ e essa imagem entrará, de certa forma, no culto cívico da cidade ${ }^{52}$ ou com a de Santiago, santo padroeiro da Reconquista. Mas nada indica que, no século XIII, essa fosse a memória que os selos procurassem preservar ou seja a de um cavaleiro errante, senhor de uma mesnada e que servia alternadamente cristãos e muçulmanos e cujo percurso, pouco conhecido, se confunde com a de muitos outros cavaleiros que viviam e subsistiam na zona de fronteira entre reinos cristãos e muçulmanos ${ }^{53}$.

Mas a utilização dos elementos guerreiros presentes nos selos de Évora e de Elvas caminhava a par da utilização de outros símbolos, tidos como representativos da história ou da vivência de uma comunidade como acontecia em Beja, onde a imagem de um touro correndo em frente às muralhas foi utilizada como entidade totémica de cidade e representativa do seu poder. Esta é, na verdade, uma representação mais dificil de explicar e de enquadrar nas suas similitudes. Proveniente de um documento tardio datado de 1345 e que se refere a uma doação particular feita à igreja de Santa Maria de Beja, a qual o concelho parece testemunhar e confirmar ${ }^{54}$, este selo incorpora um elemento usual em outros selos como é o caso do pano de muralha neste caso com três torres, ao qual junta um touro a galope, numa invocação talvez da riqueza pecuária da região.

Aqui a presença da guerra parece menos premente e a afirmação da identidade concelhia parece mergulhar as suas raízes em outros critérios.

Neste contexto, a guerra e o papel desempenhado pelas comunidades locais parece ocupar um lugar particular na simbologia de algumas das cidades do Sul de Portugal, com especial realce para Évora e Elvas. E esta assunção da guerra e da participação das comunidades como elementos identificadores das cidades, implica o reconhecimento do papel e da importância da actividade guerreira na vida económica das mesmas, muito em especial no decurso da segunda metade do século XII ou mesmo ainda ao longo da primeira metade de Duzentos, não só

\footnotetext{
${ }^{51}$ Armando Pereira, ob. cit.

52 Sobre o conceito de religião civica veja-se André Vauchez, «Introduction», in La religion Civique..., pp. 1-5.

${ }^{53}$ A construção de uma memória escrita de Évora data apenas do século XVI conforme indica o estudo de Paulo Simões Rodrigues, A Apologia da Cidade Antiga. A formação da identidade de Évora ( sécs XVI-XIX), dissertação de doutoramento em História de Arte apresentada à Universidade de Évora- policopiada, Évora, 2008.

${ }^{54}$ D. Luís de Gonzaga de Lancastre e Távora, ob.cit, no. 383.
} 
enquanto ameaça que pairava sobre a vida da urbe, mas também enquanto fonte de rendimentos. A tomada da guerra como critério identificador e sobretudo a sua manutenção ao longo das décadas posteriores, em especial a partir do momento em que tanto Évora e o seu território como Elvas deixam de ser palco de actividades militares não interessa igualmente apenas enquanto factor de hierarquização social ao organizar e dividir o corpo da sociedade em cavaleiros e peões e ao reconhecer privilégios especificos a cada um destes grupos ${ }^{55}$, mas também enquanto indicio de um modelo de cidade que a memória local procurava preservar. Ou seja a memória de uma cidade, em especial no que se refere a Évora, e de uma comunidade integrada no reino cristão por acção de um guerreiro mas através do qual se valorizava todo um corpo de cavaleiros que participaram na guerra de forma mais ou menos autónoma, que assumiram a defesa das suas muralhas nas décadas posteriores à sua conquista e que nessa acção filiavam a sua autonomia.

Noutros casos, a memória urbana mergulhava as suas raízes em outros critérios, ligados especificamente ao território no qual a comunidade se implantava e nos privilégios de que usufruía.

Mas de uma forma ou de outra é a legitimidade derivada dessa autonomia que é, de certa forma, invocada no já referido documento de acordo assinado entre o concelho e o rei D. Dinis em $1286^{56}$ e no qual o concelho eborense procurou confirmar os seus privilégios de liberdade e de isenção face ao poder senhorial. Mas é também a autonomia de um concelho ou melhor de um grupo de dominantes, a sua proeminência e a sua importância económica e politica que são reconhecidas nos textos dos forais que em 1166, 1229 e 1254 foram dados respectivamente a Évora, Elvas e Beja, embora o seu conteúdo apresente diferenças significativas.

\section{O ENQUADRAMENTO LEGISLATIVO: DOS FORAIS AOS COSTUMES}

Tanto Évora como Elvas e Beja receberam foral régio entre meados do século XII e meados de Duzentos, em contextos cronológicos bem diferentes e utilizando textos de características diversas. De uma forma geral, o foral consignava o enquadramento legislativo das povoações às quais estas cartas eram entregues, reconhecendo-lhe privilégios e imunidades, o domínio de uma determinada es-

\footnotetext{
${ }^{55} \mathrm{Na}$ verdade, estes dois grupos usufruíam de diferentes privilégios como era o caso de diferentes jurisdições. Assim ao cavaleiro de origem vilã era reconhecido o direito de ser julgado como infanção enquanto aos peões lhes era reconhecido o direito de serem julgados como cavaleiros.

${ }^{56}$ Gabriel Pereira, ob. cit. pp. 42-44.
} 
trutura social e dos critérios subjacentes à sua organização e alguns dos principios de articulação tanto entre os poderes instalados na localidade, com realce para o concelho e os representantes régios, como entre concelhos vizinhos. Em muitos casos estas cartas funcionavam igualmente como elementos de incentivo ou de fixação do povoamento, pelo que a geografia descrita pelas doações entre a segunda metade do século XII e o final da primeira metade de Duzentos nem sempre coincide com o trajecto da conquista cristã mas antes com as políticas de povoamento ou de reforço da fronteira com os restantes reinos peninsulares e com o poder muçulmano levadas a efeito por monarcas como Sancho $\mathrm{I}^{57}$.

Contudo, o foral que, em 1254, Afonso III concedeu a Beja era bem diferente daquele que tinha sido outorgado por Afonso Henriques a Évora, cerca de noventa anos antes, assim como se distanciava do foral dado a Elvas em 1229 por Sancho II. Tanto Évora como Elvas tinham recebido o modelo de foral chamado de Ávila, ou seja um texto originariamente dado a esta cidade do reino de Castela, embora o texto original seja desconhecido e recuperado para Évora em meados do século XII ${ }^{58}$. Pelo contrário Beja receberá, em meados de Duzentos, o chamado «triplice» foral dado pela primeira vez, em 1179, às cidades de Lisboa, Coimbra e Santarém ${ }^{59}$, no que significará a primeira doação deste modelo a uma cidade localizada a Sul do Tejo. A partir desta data, e tal como tinha acontecido com o modelo de Évora, também o triplice foral de 1179 entregue a Beja irradiará para outras localidades deste espaço geográfico ${ }^{60}$.

Sem pretender entrar numa análise detalhada do conteúdo destes forais é notório que tanto o modelo de Évora como o de Beja tiveram como pano de fundo o ambiente guerreiro responsável pela caracterização social subjacente a esta duas cartas. Contudo, enquanto o foral de Évora se reportava a um contexto de guerra próxima, caracterizando um núcleo no qual esta surgia não apenas como uma ameaça mas como uma actividade presente, tendo em linha de conta a conquista recente da cidade em 1165, o de Beja, embora continuasse a fazer apelo a critérios militares para justificar a superioridade de determinados grupos e a concessão especifica de privilégios, fazia-o num contexto em que a guerra com os muçulmanos se encontrava já afastada dos campos limitrofes desta cidade.

\footnotetext{
${ }^{57}$ Maria João Branco, D. Sancho I. O filho do Fundador, Lisboa, Círculo dos Leitores, 2005, pp. 172-176.

58 Sobre o foral de Ávila veja-se R. Blasco, «El problema del fuero de Ávila» in Revista de Archivos, Bibliotecas y Museos, tomo LX, 1 (1954), pp. 7-32 e José Ignácio Moreno Núnez, Ávila y su tierra en la Baja Edad Media, Ávila, 1992, pp. 138-141.

${ }^{59}$ Maria Helena Coelho, «A propósito do foral de Coimbra de 1179»in Homens, Espaços e Poderes. Séculos XI-XVI, vol. I- Notas do Viver Social, Lisboa, Livros Horizonte, 1990, pp. 105-120.

${ }^{60}$ Este foi o caso de Odemira em 1255, Monforte em 1257 e Estremoz em 1258.
} 
Desta forma, embora a guerra esteja presente na construção destes dois textos a diferença de objectivos na sua utilização parece-me ser de reter e passível de uma análise mais detalhada.

Tal como José Mattoso referia em «Identificação de um País» ${ }^{61}$ referindo-se aos costumes produzidos em diferentes localidades em especial no decurso da segunda metade do século XII e ao longo de Duzentos ${ }^{62}$ de que a sua redacção era feita em função dos interesses dos cavaleiros e enquanto meio de defesa e de imposição dos interesses deste grupo dominante, também os forais correspondiam a interesses não apenas do outorgante mas também dos seus receptores. Claro que, no caso de Beja, a intervenção dos destinatários parece mais atestada pela indicação de que o texto do triplice foral teria sido dado por Afonso III a pedido dos «homens e vassalos» responsáveis pelo povoamento da cidade, leiase pelos grupos responsáveis pelo governo e defesa de Beja, enquanto no caso de Évora e de Elvas o rei se assume como outorgante de um texto destinado a cidades de fronteira mas dirigindo-se claramente aos que protagonizavam a sua defesa $^{63}$.

$\mathrm{Na}$ verdade, a participação na defesa da cidade constitui uma questão crucial na economia do texto dos forais de Évora e de Elvas e a não participação de dois terços dos cavaleiros no fossado, ou seja nas campanhas ofensivas, ou no apelido implicaria o pagamento de uma penalização, superior no caso desta última já que implicava a defesa da localidade em caso de ataque.

Desta forma, o foral de 1166 identificava com clareza uma sociedade que se estruturava em função da guerra e no interior da qual se destacavam dois grupos: o dos cavaleiros e o dos peões, com privilégios e direitos diferenciados, aos quais se juntava um conjunto numeroso e diversificado de dependentes sem obrigações militares e ligados ao seu senhor ${ }^{64}$.

Contudo, como sociedade de fronteira que era o grupo dos cavaleiros não era ainda um espaço fechado à mobilidade social e a cristalização social que as décadas seguintes viriam a ditar com o acentuar da tendência para o encerramento dos grupos dominantes e de aristocratização das camadas ligadas ao exercicio do poder concelhio, não era ainda uma realidade total. Assim, o foral

${ }^{61}$ José Mattoso, ob. Cit., vol. I, pp. 350-351.

${ }^{62}$ Luís Lindley Cintra, A linguagem dos foros de Castelo Rodrigo : seu confronto com a dos foros de Alfaiates, Castelo Bom, Castelo Melhor, Coria, Cáceres e Usagre : contribuição para o estudo do leonês e do galego-português do século XIII, Lisboa, Sá da Costa, 1959.

${ }^{63}$ Alexandre Herculano, Portugaliae monumenta historica : a saecvlo octavo post Christvm vsque ad quintvmdecimvm - Leges et consuetudines, Lisboa, Academia das Ciências, 1810-1877, pp. 640-644.

${ }^{64}$ José Mattoso, ob. cit., vol. I pp. 367-376. 
de Évora coloca-nos perante uma cavalaria «aberta» no dizer de Monsalvo Antón ${ }^{65}$, à qual se ascendia a partir da posse de um conjunto de bens, entre os quais estavam incluídos bens móveis e imóveis, com realce para o gado, tipico de uma economia de guerra ${ }^{66}$. Neste contexto a posse de um cavalo e a participação na guerra decorria de uma obrigação inerente ao usufruto de um determinado estatuto económico expresso na posse de bens e logo baseava-se em critérios económicos que não deixavam de determinar a hierarquia de possidentes. Mas a esta hierarquia correspondia igualmente uma valorização social do lugar ocupado no desempenho militar e, como tal, o grupo que se apresentava como dominante confundia-se com o que lutava a cavalo e ocupava, em casos como o de Beja, posições de dianteira nas ofensivas militares.

No entanto, no caso desta última localidade o grupo dos cavaleiros apresentava-se já com diferentes contornos daqueles que tinham estado subjacentes aos forais de Évora e de Elvas. Estes dirigem-se, na verdade, a povoações recentemente conquistadas, nas quais a guerra se assumia como uma actividade presente e a cuja pressão as povoações se encontravam submetidas. Desta forma não apenas era reconhecida a superioridade militar dos cavaleiros vilãos, mas também um conjunto de privilégios que os reconhecia como grupo dominante no contexto social destas duas localidades. O privilégio de serem julgados como infanções, a isenção do pagamento de jugada e de direitos pela utilização das tendas e dos moinhos no caso dos habitantes de Évora, conferia-lhes um especial estatuto especialmente completado no caso de Beja como veremos mais adiante.

Com efeito, os forais outorgados a Évora e Elvas colocam-nos perante sociedades hierarquizadas, organizadas para e em função da guerra, com um nível relativamente incipiente de organização administrativa e a quem era assegurada a manutenção do laço com o poder régio através do compromisso assumido pelo rei de a localidade não ser dada a outro senhor, privilégio que o concelho se preocuparia em ver reiterado algumas décadas mais tarde em 1286, num contexto bem diferente do de 1166.

De certa forma, o contexto de outorga do foral a Beja aproxima-se mais daquele em que o acordo entre o concelho de Évora e D. Dinis foi celebrado. Em meados de Duzentos a guerra continuava a ser utilizada como um critério de diferenciação social e o lugar ocupado na hierarquia militar não deixava de

65 J. Maria Monsalvo Antón, «Transformaciones Sociales y relaciones de poder en los concejos de frontera, siglos XI-XIII. Aldeanos, vecinos y caballeros ante las instituciones municipales» in Relaciones de Poder, de producción y parentesco en la Edad Media y Moderna, Madrid, CSIC, 1990, pp. 107-170.

${ }^{66}$ Em Évora todo aquele que possuísse uma «aldeia», de um casal de bois, 40 ovelhas, um burro e dois leitos era obrigado a ter cavalo. Gabriel Pereira, ob.cit, p. 17. 
reforçar uma estrutura social marcada pela desigualdade. Mas o lugar proeminente ocupado pelos cavaleiros de Beja na defesa da cidade e nas expedições organizadas vêm, de certa forma, confirmar uma hierarquia social que repousava já, de maneira clara, em critérios que não se esgotavam na valorização social da função guerreira mas na importância política e económica dos grupos que a exerciam ${ }^{67}$.

Antes de mais a referência a que este modelo de foral teria sido dado a pedido dos habitantes de Beja indicia, para lá das fórmulas tabeliónicas, uma intervenção dos destinatários no sentido de influenciarem a escolha de um texto que reconhecesse privilégios e consignasse formas de vivência já relativamente instaladas. Porque, na verdade, a doação de foral a Beja não se enquadra numa conjuntura de pós reconquista nem de guerra premente, definidas que estão nestes anos, em grande parte, as fronteiras do reino de Portugal e do Algarve.

Assim, o foral de 1254 reconhece e outorga especiais privilégios aos que eram identificados como homens bons e cavaleiros de Beja, em especial a capacidade de organizarem expedições militares aos campos em redor e de liderarem a defesa da cidade, a par do rei ou isoladamente. Na verdade, Beja contribuíria com 60 cavaleiros quando o rei o pedisse devendo estes ocupar uma posição dianteira na expedição organizada, referência que denota bem a importância do grupo em causa. Da mesma forma, eram reconhecidos à cidade integrada no reino cerca de 20 anos antes um conjunto de direitos e um assinalável nível de autonomia na governação da comunidade, dando ao concelho a posse da almotaçaria e a capacidade de nomeação dos alvazis, o privilégio de o alcaide ser sempre oriundo de Beja e a obrigação dos nobres que aí residissem de servirem como cavaleiros ${ }^{68}$. A par, o texto do foral reconhecia aos homens e vassalos de Beja a isenção do pagamento da jugada, do foro de carregar o vinho de fora pelo relego e da portagem em todo o reino.

No seu conjunto, o total de privilégios outorgados e o grau de autonomia conferido ao concelho de Beja, coloca-nos perante uma comunidade com um grau de organização e de reivindicação superior ao de Évora ou ao de Elvas, cuja influência se reflectia mesmo na escolha do próprio modelo de foral e perante um grupo cioso das suas prerrogativas, identificado como o grupo dos cavaleiros e homens bons de Beja ${ }^{69}$.

${ }^{67}$ J. M Monsalvo Anton, ob. cit., especialmente pp. 124-126.

${ }^{68}$ No caso de Évora a nomeação do alcaide da cidade e do seu termo caberia ao pretor nomeado pelo rei de acordo com um documento de Afonso III de 1264. Gabriel Pereira, ob. Cit, pp. 25-26.

${ }^{69}$ Hermenegildo Fernandes, Organização do espaço e sistema social no Alentejo Medievo : o caso de Beja, Lisboa,dissertação de mestrado-poliopiada, 1991. 
Estamos pois perante dois momentos de assunção e de constituição dos grupos locais. Embora a guerra surja nos dois modelos de foral como um critério de distinção e de identificação social a verdade é que enquanto em Évora o grupo dos cavaleiros surge ainda como um grupo relativamente aberto, que se caracterizava pela posse de bens e que mantinha acentuadas relações de dependência com um variado e multifacetado grupo de dependentes entre os quais se incluíam hortelãos, solarengos e quarteiros, em Beja o conjunto de cavaleiros e de homens bons parece ter atingido um nível de formalização superior e de consciência mais clara das suas prerrogativas, bem como do papel central jogado pelo rei na legitimação dessa elite. Se bem que responsáveis pelo exercício da guerra e pela defesa da localidade, o foral não procura assegurar quem é obrigado a manter cavalo ou a participar nos apelidos mas antes um conjunto de privilégios e isenções a quem se dedica à prática da guerra mas que não esgota nesta a amplitude das suas funções.

De certa forma, este grau de formalização de uma elite e de consciência da necessidade de reconhecimento de um conjunto de privilégios que legitime a sua superioridade social só é atestada para Évora nos documentos da segunda metade de Duzentos em especial nos foros e costumes produzidos ou pelos menos copiados nas décadas de 60, 80 e 90 da segunda metade do século XIII.

Tendo sido estes textos publicados por Gabriel Pereira a partir da obra de Alexandre Herculano ${ }^{70}$ a fixação dos textos originais e a datação da sua produção coloca vários problemas decorrentes do facto de estes Costumes terem chegado até nós através de cópias enviadas pelo Concelho de Évora a outros concelhos limitrofes a pedido do rei ou em diplomas comunicados entre concelhos. Desta forma, apenas um estudo sistemático e comparativo dos vários foros e costumes permitiria estabeler ilações e cronologias próximas para a sua produção.

Não obstante estas limitações, alguns dos dados incluídos nestes textos merecem uma reflexão comparativa enquanto textos que procuram completar ou reorientar alguns dos elementos incluídos no foral e estabelecem, de forma clara, os privilégios de que beneficiavam determinados grupos. Tal como José Mattoso escreveu os foros e costumes foram escritos para os cavaleiros vilãos dos concelhos e com o intuito de reforçarem a sua posição no espaço político do conce1 ho ${ }^{71}$. Desta forma, não surpreendem as disposições relativas ao favorecimento do cavaleiro tanto face ao peão como face ao dependente e expresso nas penas menores que incidiam sobre aquele grupo, na valorização do seu testemunho em casos de justiça, no estabelecimento de monopólios concelhios nos quais estes

${ }^{70}$ Gabriel Pereira, ob. cit., p. 25-32 e pp 35-40.

71 J. Mattoso, Identificação de um país, vol. I, p. 350-352. 
cavaleiros não deixariam de participar como acontecia com a definição e imposição dos pesos e medidas utilizados. Da mesma forma, os vários artigos que referem os dependentes fazem-no no sentido do reforço dos laços que os uniam aos seus senhores, retirando-lhes espaço de intervenção próprio na vida da cidade e tornando os seus protectores em mediadores da sua inserção no espaço urbano.

Mas a par dos cavaleiros, peões e dependentes os foros e costumes de Évora marcam ainda uma acentuada diferença entre os vizinhos de Évora e os homens oriundos de fora da cidade ${ }^{72}$ e esta parece ser uma oposição particularmente reiterada ao longo destes textos. Com efeito, para lá da reafirmação de uma hierarquia que embora utilize conteúdos funcionais e militares para se identificar se articulava cada vez mais em torno das actividades económicas e do controle de bens tal como as disposições relativas à protecção das actividades exercidas deixam entrever, todos estes textos oriundos da segunda metade de Duzentos acentuam a diferenciação entre o vizinho de Évora e o «homem de fora», ao beneficiarem aquele com um conjunto de medidas protectoras e de isenção proibidas aos demais. Aliás, a própria construção dos textos dos Costumes evidencia que era predominantemente aos vizinhos de Évora que estes textos eram dirigidos, definindo assim o âmbito de aplicação das disposições aí incluídas.

Assim, estes dois símbolos: o selo, criado pela comunidade concelhia e utilizado enquanto símbolo de identificação externa de uma cidade e o foral, especialmente no caso de Évora e de Elvas e enquanto texto de reconhecimento da existência e da autonomia de uma comunidade por parte do rei, concretizam e representam uma primeira fase no processo de construção de uma identidade reconhecida pelas comunidades e imposta externamente.

Próximas das vivências guerreiras atestadas nestes símbolos, estas comunidades urbanas construíram uma parte da sua legitimidade sobre a capacidade militar evidenciada pelas suas elites e procuraram a ratificação recorrente dos privilégios obtidos através da afirmação do esforço desenvolvido no contexto da conquista e manutenção dos espaços urbanos.

No caso de Évora os foros e costumes sobreviventes permitem completar um quadro legal e seguir as adaptações realizadas no decurso do século XIII, num contexto político no qual a guerra tinha já perdido premência mas para o qual os critérios militares se mantêm como referencial teórico de uma hierarquização

\footnotetext{
${ }^{72} \mathrm{Na}$ verdade todo o texto foi construído tendo em linha de conta a necessidade de marcar as diferenças entre os «vizinhos» de Évora e os oriundos de fora da cidade, os quais estavam sujeitos a diferentes penalidades, diferentes tipos de castigo e isenções. Estas diferenças eram cruciais na definição da hierarquia social tal como já foi demonstrado por diferentes autores em alguns estudos de caso. Veja-se a título de exemplo o estudo já citado de Philip Daileader, True Citizens. Violence, Memory and Identity in Medieval Perpignan.
} 
social. E algo de semelhante acontece com Beja. Para esta cidade do Sul a guerra continuava presente na legitimação da desigualdade social mas os critérios de hierarquização enquadravam-se cada vez mais na realidade económica, na capacidade de acesso e de controle dos bens e do poder económico e político ${ }^{73}$.

O que está pois em causa é uma evolução temporal entre o inicio da segunda metade do século XII e um contexto de guerra de fronteira e a segunda metade de Duzentos, num enquadramento de consolidação dos núcleos de povoamento, acentuada pelas diferenças originais entre as formas de organização entre diferentes localidades e a manutenção do predomínio de um grupo de cavaleiros de origem vilã e com articulações ainda relativamente limitadas a grupos da nobreza.

Com efeito, a paragem da guerra, a reordenação das hierarquias económica e social de muitas destas localidades, o acentuar da articulação entre o poder régio e as elites urbanas ditaria a necessidade de construção de novos conjuntos de reivindicações e pedidos, a definição de novos argumentos de legitimação e de organização social e igualmente de novas formas de pensar e de representar a identidade urbana. De certa forma, o «bem comum», a necessidade de defender o «prol comum» da população e a reafirmação da ligação ao rei insinuavam-se por entre o afastamento dos palcos militares.

${ }^{73}$ Para algumas das questões ligadas à classificação social em meio urbano veja-se Mário Farelo, A Oligarquia camarária de Lisboa (1325-1433), pp. 178-188 e James Powers, A Society organized for war. The Iberian municipal militias in the central middle Ages, 1000-1284, Berkeley-Los Angeles- London, University of California Press, 1987. 